\title{
Theoretical Framework for Creep Effect Analysis of Axially Loaded Short CFST Columns under High Stress Levels
}

\author{
Shiwei Li $\left(\mathbb{D},{ }^{1,2}\right.$ Yongqing Yang, ${ }^{1}$ Wangqing Wen, ${ }^{2}$ and Aiguo Yan $^{2}$ \\ ${ }^{1}$ College of Civil Engineering, Southwest Jiaotong University, Chengdu 610031, China \\ ${ }^{2}$ China Railway Siyuan Survey and Design Group Company Limited, Wuhan 430063, China \\ Correspondence should be addressed to Shiwei Li; lishiwei1987@my.swjtu.edu.cn
}

Received 22 January 2020; Revised 24 February 2020; Accepted 5 May 2020; Published 21 May 2020

Academic Editor: Khalid Abdel-Rahman

Copyright (c) 2020 Shiwei Li et al. This is an open access article distributed under the Creative Commons Attribution License, which permits unrestricted use, distribution, and reproduction in any medium, provided the original work is properly cited.

Due to its excellent mechanical performances, axially loaded concrete-filled steel circular tube (CFST) columns have been widely used in structural engineering. As an important long-term behaviour of CFST structures, the creep has an obvious nonlinear property under high stress levels, which makes the influence of creep more complicated. In this study, to analyze the impacts of nonlinear creep effect on the behaviour of axially loaded short CFST columns, a complete theoretical framework for coupling analysis of 3D creep effect and material nonlinearity was presented. First, the concrete damaged plasticity model with a uniform constraint (UCCDP) was established to simulate the plasticity and damage evolution of a concrete core. Next, based on the UCCDP, a method of 3D nonlinear creep analysis and a corresponding numerical analysis method were established and implemented in the ABAQUS secondary platform. Finally, by comparing the predicted results with the experimental results, it was observed that the method proposed to predict the creep of axially loaded short CFST columns had satisfactory accuracy.

\section{Introduction}

Owing to their merits of high compressive strength, durability, construction, and low cost, concrete-filled steel tubes (CFST) have been widely used in structures $[1,2]$. Nevertheless, the results obtained by intensive research have demonstrated that creep causes structural deformation and internal force redistribution, which has an important effect on the long-term mechanical behaviour of CFST columns [3]. Theoretical and experimental studies have demonstrated that there exists a nonlinear relationship between creep and stress, when the stress of the concrete core exceeds a certain level $\left(0.6 f_{c}\right)$, which obviously indicates nonlinear characteristics $[4,5]$. Fu [6] analyzed the stress levels of a concrete core in super-high-rise buildings, such as the Harbour Building in Xiamen city and the Dacheng Financial \& Business Center in Kunming city, and reported that the stress levels have reached $0.69 f_{c}$. The nonlinear creep effect does not only cause excessive deformation, but also has further impact on dynamic structural characteristics [7]. To analyze the long-term behaviour of CFST columns under high stress levels, it is necessary to establish a nonlinear creep analysis theory.

For the nonlinear creep theory, three different theories have been proposed: one is to establish a rheological model to simulate the creep characteristic directly through the uniaxial strain creep test under high stress level [8]; the second is to establish the nonlinear functional relationship between the creep responses and the stresses based on the uniaxial creep characteristic under low stress levels; the third is to establish the nonlinear creep constitutive equations of concrete under high stress levels by using damage mechanics [9-12]. For the first two theories which are both based on the creep test under uniaxial stress, it is difficult to apply to the creep analysis under a complex stress state. For the third kind of method, the reason for the nonlinear creep is attributed to the material damage evolution, and the application is also more convenient; however, the results of existing studies have various shortcomings. Li and Qian [9] established the elastic creep damage analysis model by using continuum damage mechanics, but did not consider the influence of the concrete's plastic behaviour. Huang and 
Xiang [12] proposed a method of analyzing the nonlinear creep effect on concrete by using the classical uniaxial stressstrain relationship (Hognestad model). However, the uniaxial stress-strain curve does not describe the nonlinear behaviour of concrete completely.

Additionally, for CFST columns with axial compression, the concrete core is always under a uniform constraint, i.e., the creep has obvious three-dimensional (3D) characteristics $[13,14]$.

In this study, a new theoretical framework for modeling the 3D nonlinear creep effect of axially loaded CFST columns with high stress levels is proposed on the basis of continuous damage mechanics and concrete elastic-plastic mechanics. The first part of this theoretical framework is the concrete damaged plasticity model under a uniform constraint (UCCDP) to simulate the plasticity and damage evolution of concrete. The second part is the $3 \mathrm{D}$ nonlinear creep analysis model and the corresponding numerical analysis method. Finally, using the creep prediction B4 model [15] and the finite element (FE) package ABAQUS, the numerical analysis method was implemented into the ABAQUS secondary platform, and the analytical results were compared with the experimental results in different stress levels.

\section{Constitutive Model for Concrete under Uniform Constraint}

The concrete damaged plasticity (CDP) model has been widely used in engineering projects, owing to its ease of use $[16,17]$. The CDP model mainly includes the Lubliner yield criterion, Drucker-Prager plastic flow criterion, and damage evolution and hardening criterion. However, this model is mainly suitable to the analysis of the elastic-plastic behaviour of concrete structures under low confining stress [17]. The concrete core of circular CFST columns under axial compression is in the triaxial compression state, and the confining pressure has already affected the mechanical behaviour of concrete. This is a convenient and effective method to modify the CDP model and analyze the elasticplastic behaviour of concrete under uniform confinement. Therefore, in this paper, the defects of the Lubliner yield criterion under uniform constraints are discussed, and the modification of the yield and plastic flow criteria is explained.

\subsection{Yield Criterion}

2.1.1. Defect of the Lubliner Yield Criterion in CFST. The Lubliner yield criterion is a fundamental part of the concrete constitutive model and is always used to determine whether concrete has entered the plastic stage. The Lubliner yield criterion is expressed as follows:

$$
F\left(\bar{\sigma}_{i j}, \widetilde{\varepsilon}^{p l}\right)=\frac{1}{1-\alpha}\left(\sqrt{3 J_{2}}+\alpha I_{1}+\beta \widehat{\bar{\sigma}}_{\max }-\gamma-\widehat{\bar{\sigma}}_{\max }\right)-c,
$$

where $\bar{\sigma}_{i j}$ is the effective stress; $\widetilde{\mathcal{E}}^{p l}$ is the equivalent plastic strain; are the Macaulay brackets and $\langle x\rangle$ is taken as $(|x|+x) / 2 ; I_{1}$ is the first stress invariant; $J_{2}$ represents the second deviatoric stress invariant; $\widehat{\bar{\sigma}}_{\max }$ is the maximum effective stress eigenvalue; $c$ is the cohesion; $\alpha, \beta$, and $\gamma$ are the undetermined parameters. $\alpha$ and $\beta$ are determined by the uniaxial tensile strength, compressive strength, and biaxial isobaric strength, and $\gamma$ is determined by the tensile meridian (TM) and compressive meridian (CM) [16, 17]. However, for concrete in axially compressed CFST columns, the abovementioned method of determining $\gamma$ has unavoidable drawbacks.

The expression of TM and CM in Haigh-Westergaard stress space can be expressed as follows:

$$
\begin{aligned}
& (\gamma+3 \alpha) \xi+\frac{(2 \gamma+3)}{\sqrt{2}} \rho=\sqrt{3}(1-\alpha) c(\mathrm{TM}), \\
& (\gamma+3 \alpha) \xi+\frac{(\gamma+3)}{\sqrt{2}} \rho=\sqrt{3}(1-\alpha) c(\mathrm{CM}),
\end{aligned}
$$

where $\xi$ is the hydrostatic pressure taken as $-I_{1} / 3$ and $\rho$ is the von Mises equivalent stress taken as $\rho=\left(3 J_{2}\right)^{1 / 2}$.

At a given $\xi$ in triaxial compression, the $\rho$ ratio in equations (2) and (3) is defined as $K_{c}, K_{c}=(\gamma+3) /(2 \gamma+3)$. The value of $K_{c}$ determines the shape of the trace line in the deviatoric plane, as shown in Figure 1. Because the value of $K_{c}$ is determined, the value of parameter $\gamma$ is also determined, which means that the opening shape of the yield surface is determined by $\gamma$.

Figure 2 shows the von Mises equivalent stress $(\rho)$ versus the negative hydrostatic pressure $(-\xi)$ curves in TM and CM. The angle between the curves and the $-\xi$ axis is defined as $\varphi$. Thus, the slope of the curves can be expressed as follows:

$$
\begin{aligned}
& \tan \varphi_{\mathrm{TM}}=\frac{\sqrt{2}(\gamma+3 \alpha)}{2 \gamma+3}, \\
& \tan \varphi_{\mathrm{CM}}=\frac{\sqrt{2}(\gamma+3 \alpha)}{\gamma+3} .
\end{aligned}
$$

The value of the slopes indicates the opening angle of the yield surface. Therefore, parameter $\gamma$ influences both the opening shape and the opening angle of the yield surface. However, after selecting an appropriate parameter $\gamma$ to determine the opening shape, the yield surface may not be able to obtain an appropriate opening angle.

2.1.2. Calibration of the Parameter $\gamma$. For concrete in axially compressed circular CFST columns, the opening shape of the yield surface should be controlled by the slope of the CM [18]. Because of the confining pressure exerted by the steel tube, the compressive strength of the concrete core is improved as expressed by the following equation:

$$
f_{c c}=f_{c}+k \sigma_{l}
$$

where $f_{c c}$ is the compressive strength of concrete under a uniform constraint, $\sigma_{l}$ is the confining pressure, and $k$ is the strength enhancement factor. 


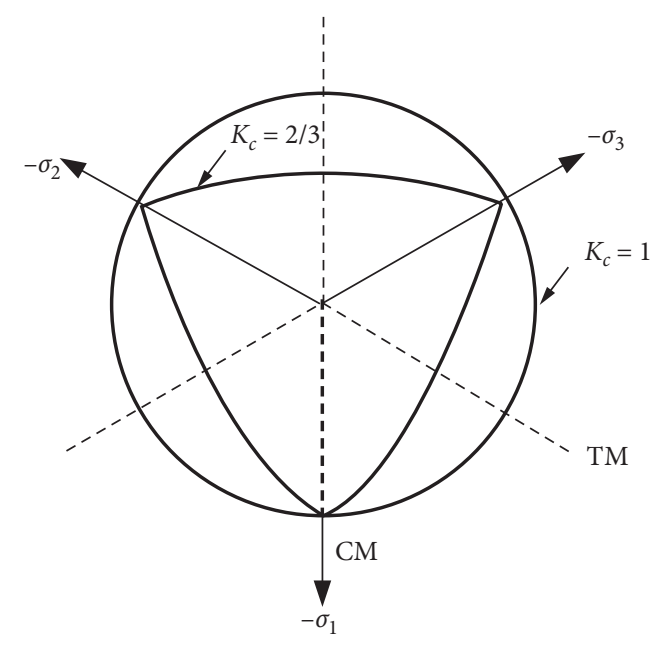

Figure 1: Deviatoric traces in the deviatoric plane.

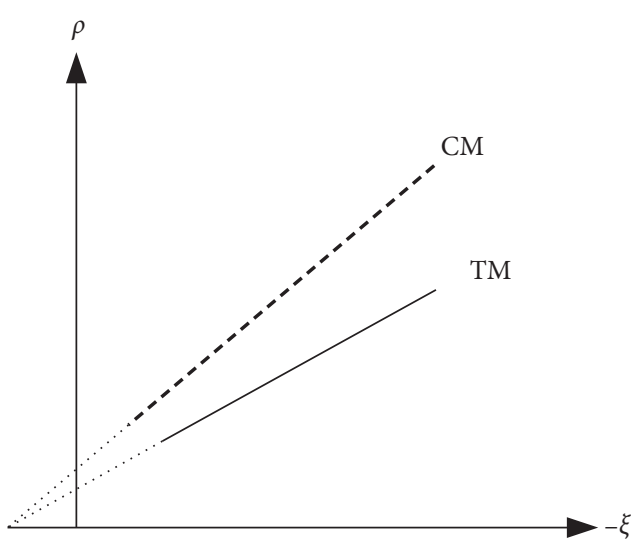

Figure 2: The TM and CM.

When the concrete core fails under uniform confinement, $I_{1}=f_{c c}-2 \sigma_{l}$ and $J_{2}=1 / 3\left(f_{c c}-\sigma_{l}\right)^{2}$. By substituting these into equation (1), we obtain the following equation:

$$
\gamma=(1-\alpha) k-(1-2 \alpha)
$$

According to the Mohr-Coulomb criterion [17],

$$
\frac{1+\sin \varphi}{1-\sin \varphi} \sigma_{\max }-\sigma_{\min }=f_{c}
$$

where $\varphi$ is the internal friction angle of concrete.

For concrete under a uniform constraint, $\sigma_{\max }=-\sigma_{l}$ and $\sigma_{\min }=-f_{c c}$. By substituting $\sigma_{\max }, \sigma_{\min }$, and equation (8) into equation (7), $\gamma$ can be rewritten as follows:

$$
\gamma=(1-\alpha) \frac{1+\sin \varphi}{1-\sin \varphi}-(1-2 \alpha)
$$

The angle of internal friction can be calculated as follows [19]:

$$
\varphi=13.84^{\circ} \cdot e^{\left(-21.73 \widetilde{\varepsilon}^{-p l}\right)}+22.41^{\circ}
$$

The result of comparing the original calibration method with the current calibration method is presented in Figure 3.
2.2. Flow Rule. As part of the constitutive model, the flow criterion is used to determine the plastic deformation of concrete when the concrete enters the plastic state. The widely used Drucker-Prager flow criterion, which is expressed by equation (11), was adopted in this study:

$$
G=\sqrt{\left(\varsigma \sigma_{t 0} \tan \psi\right)^{2}+3 J_{2}}+\frac{1}{3} I_{1} \tan \psi,
$$

where $\zeta$ is the eccentricity ratio, always taken as $0.1, \sigma_{t 0}$ is the uniaxial tensile strength of concrete, and $\psi$ is the concrete's dilation angle.

To accurately analyze the plastic deformation, we must obtain a reasonable dilation angle $(\psi)$. The physical meaning of $\psi$ represents the plastic deformation rate of the concrete. Thus, a larger dilation angle means a larger plastic deformation rate and leads to the steel tube having a stronger constraint effect on concrete [20]. Wang et al. [21] investigated the relationship between the dilation angle and the hoop stress of ultrahigh-performance concrete, but did not consider the effect of material damage evolution, which leads to an obvious underestimation of the components' plastic deformation. Based on this, the calculation method of the dilation angle considering the influence of damage evolution was deduced again. The strain of concrete includes elastic strain and plastic strain, as expressed by the following equation:

$$
\varepsilon_{i j}=\varepsilon_{i j}^{e}+\varepsilon_{i j}^{p}
$$

According to the theory of elastic-plastic mechanics, the plastic strain increment can be expressed as follows:

$$
\mathrm{d} \varepsilon_{i j}^{p}=\lambda \frac{\partial G}{\partial \sigma_{i j}}
$$

where $\lambda$ is a nonnegative scalar.

The circumferential plastic strain $\left(\varepsilon_{1}^{p}\right)$, the radial plastic strain $\left(\varepsilon_{2}{ }^{p}\right)$, and the longitudinal plastic strain $\left(\varepsilon_{3}{ }^{p}\right)$ can be expressed as follows:

$$
\begin{aligned}
& \varepsilon_{1}^{p}=\varepsilon_{2}^{p}=\varepsilon_{1}-\frac{1}{E_{c}(1-d)}\left(\sigma_{1}-2 v \sigma_{3}\right), \\
& \varepsilon_{3}^{p}=\varepsilon_{3}-\frac{1}{E_{c}(1-d)}\left(\sigma_{3}-2 v \sigma_{1}\right),
\end{aligned}
$$

where $d$ is the damage factor as a function of equivalent plastic strain and $v$ is the elastic Poisson's ratio of concrete.

By substituting equation (11) into equation (13), we obtain the following equations:

$$
\mathrm{d} \varepsilon_{1}^{p}=\mathrm{d} \lambda\left[\frac{1}{3} \tan \psi-\frac{1}{2 \sqrt{\left(\varsigma \sigma_{t 0} \tan \psi\right)^{2}+3 J_{2}}}\left(\sigma_{2}-2 \sigma_{1}+\sigma_{3}\right)\right],
$$

$$
\mathrm{d} \varepsilon_{2}^{p}=\mathrm{d} \lambda\left[\frac{1}{3} \tan \psi-\frac{1}{2 \sqrt{\left(\varsigma \sigma_{t 0} \tan \psi\right)^{2}+3 J_{2}}}\left(\sigma_{1}-2 \sigma_{2}+\sigma_{3}\right)\right],
$$




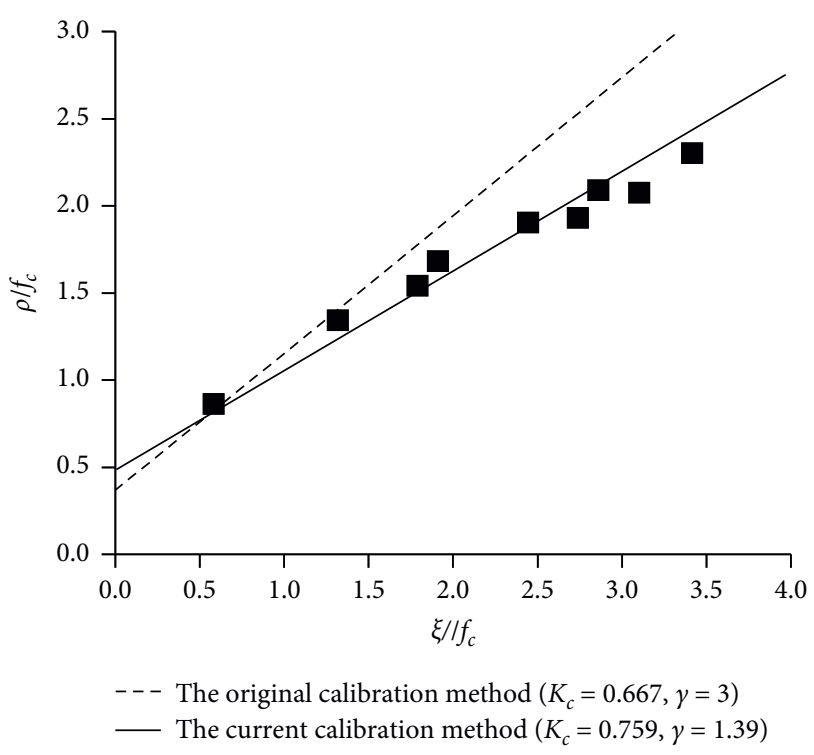

Figure 3: Calibration for the yield criterion of uniform confined concrete.

$$
\mathrm{d} \varepsilon_{3}^{p}=\mathrm{d} \lambda\left[\frac{1}{3} \tan \psi-\frac{1}{2 \sqrt{\left(\varsigma \sigma_{t 0} \tan \psi\right)^{2}+3 J_{2}}}\left(\sigma_{1}-2 \sigma_{3}+\sigma_{2}\right)\right] .
$$

Because $\zeta$ is always taken as $0.1, \sqrt{\left(\varsigma \sigma_{t 0} \tan \psi\right)^{2}+3 J_{2}}$ can be approximately replaced by $\sqrt{3 J_{2}}$.

By adding up equations (16) to (18), we obtain

$$
\mathrm{d} \varepsilon_{1}^{p}+\mathrm{d} \varepsilon_{2}^{p}+\mathrm{d} \varepsilon_{3}^{p}=\mathrm{d} \lambda \cdot \tan \psi
$$

Equation $(18)-0.5 \times$ (equation $(16)+$ equation gives

$$
\mathrm{d} \varepsilon_{3}^{p}-0.5\left(\mathrm{~d} \varepsilon_{1}^{p}+\mathrm{d} \varepsilon_{2}^{p}\right)=-\frac{3}{2} \mathrm{~d} \lambda
$$

By substituting equation (20) into equation (19), we obtain

$$
\begin{aligned}
& \tan \psi=-\frac{3}{2} \frac{\mathrm{d} \varepsilon_{3}^{p}+2 \mathrm{~d} \varepsilon_{1}^{p}}{\mathrm{~d} \varepsilon_{3}^{p}-\mathrm{d} \varepsilon_{1}^{p}}=\frac{\sqrt{3}}{2} \frac{\mathrm{d} I_{1}^{p}}{\sqrt{\mathrm{d} J_{2}^{\prime p}}} \\
& \mathrm{~d} I_{1}^{\prime} p=\mathrm{d} \varepsilon_{1}^{p}+\mathrm{d} \varepsilon_{2}^{p}+\mathrm{d} \varepsilon_{3}^{p}, \\
& \mathrm{~d} J_{2}^{\prime} p=\frac{1}{6}\left[\left(\mathrm{~d} \varepsilon_{1}^{p}-\mathrm{d} \varepsilon_{2}^{p}\right)^{2}+\left(d \varepsilon_{1}^{p}-\mathrm{d} \varepsilon_{3}^{p}\right)^{2}+\left(\mathrm{d} \varepsilon_{2}^{p}-\mathrm{d} \varepsilon_{3}^{p}\right)^{2}\right]
\end{aligned}
$$

The positive value of $\tan \psi$ represents the volumetric dilation, and its negative value represents the volumetric contraction. If reliable test data are not available, the dilation angle can be calculated by the following equation [19]:

$$
\psi= \begin{cases}56.3\left(1-\xi_{c}\right), & \xi_{c} \leq 0.5, \\ 6.672 e^{7.4 / 4.64+\xi_{c}}, & \xi_{c}>0.5,\end{cases}
$$

where $\xi_{c}$ is the confinement coefficient and is taken as $\left(A_{s} f_{y} / A_{c} f_{c}^{\prime}\right) ; A_{c}$ and $A_{s}$ are the sectional area of the steel tube and concrete core, respectively; $f_{y}$ is the yield strength of the steel tube; and $f_{c}^{\prime}$ is the cylinder compressive strength of the concrete core.

2.3. Damage Evolution and Hardening Rule. By introducing the damage factor $d$, the relationship between the strain tensor $\left(\sigma_{i j}\right)$ and the plastic strain $\left(\varepsilon_{i j}\right)$ can be expressed as follows [16]:

$$
\sigma_{i j}=(1-d) D_{i j k l}^{0} \cdot\left(\varepsilon_{i j}-\varepsilon_{i j}^{p}\right)
$$

where $D_{i j k l}^{0}$ is the concrete's initial elastic matrix and $d$ is the damage index expressed as follows:

$$
(1-d)=\left(1-s_{t} d_{c}\right)\left(1-s_{c} d_{t}\right)
$$

where $\mathrm{d} t$ and $\mathrm{d} c$ are the tensile and compressive damage indices of concrete, respectively, as expressed in equations (27) to (29); $s_{t}$ and $s_{c}$ represent the recovery functions of the damage index, which consider the effects of crack closure and the reduction of tensile strength caused by compressive damage, as expressed in equations (30) to (31):

$$
\left\{\begin{array}{l}
d_{t}=d_{t}\left(\widetilde{\varepsilon}_{t}^{p}\right) \\
d_{c}=d_{c}\left(\widetilde{\varepsilon}_{c}^{p}\right)
\end{array}\right.
$$

$$
\begin{aligned}
& \widetilde{\mathcal{\varepsilon}}^{\mathbf{p}}=\left[\begin{array}{c}
\widetilde{\varepsilon}_{t}^{p} \\
\widetilde{\varepsilon}_{c}^{p}
\end{array}\right], \\
&\left\{\begin{array}{l}
\mathrm{d} \widetilde{\varepsilon}_{t}^{p}=r(\sigma) \mathrm{d} \widehat{\varepsilon}_{\max }^{p}, \\
\mathrm{~d} \widetilde{\varepsilon}_{c}^{p}=-(1-r(\widehat{\sigma})) \mathrm{d} \widehat{\varepsilon}_{\min }^{p},
\end{array}\right. \\
& r(\widehat{\sigma})=\frac{\sum_{i=1}^{3} \widehat{\sigma}_{i}}{\sum_{i=1}^{3}\left|\widehat{\sigma}_{i}\right|} \quad 0 \leq r(\widehat{\sigma}) \leq 1, \\
& s_{t}=1-\omega_{t} r(\widehat{\sigma}), \quad 0 \leq \omega_{t} \leq 1, \\
& s_{c}=1-\omega_{c}(1-r(\widehat{\sigma})), \quad 0 \leq \omega_{c} \leq 1 .
\end{aligned}
$$

For axially loaded short CFST columns, $r(\widehat{\sigma})$ equals 0 because $0>\sigma 1=\sigma 2>\sigma 3$. Additionally, $s_{t}$ is always taken as 1 and $s_{c}$ is always taken as 0 .

$$
\begin{aligned}
(1-d) & =1-d_{c}\left(\widetilde{\varepsilon}_{c}^{p}\right), \\
\mathrm{d} \widetilde{\varepsilon}_{i j}^{p} & =\mathrm{d} \widetilde{\varepsilon}_{c}^{p}=-\mathrm{d} \widehat{\varepsilon}_{\min }^{p l} .
\end{aligned}
$$

The evolution law of the concrete yield surface (hardening criterion) is still driven by the equivalent plastic strain $\left(\widetilde{\varepsilon}_{i j}^{p}\right)$ as expressed by equation (33). 


\section{Analysis Model for 3D Nonlinear Creep Effect}

3.1. Processing of 3D Characteristic Creep Effect. As mentioned above, the creep has an obvious 3D characteristic for CFST columns. However, research on the creep law under multiaxial stress states is ongoing and a prediction model that can be used directly has not yet been developed. Therefore, by introducing the concept of creep Poisson's ratio [22], the creep law under uniaxial stress is extended to multiaxial stress states. This can be considered as a simple and feasible method when the experimental data are insufficient.
Neville et al. [23] summarized the results of existing experimental research and reported that the creep Poisson's ratio $\mu_{c p, i}$ can be expressed as follows:

$$
\mu_{c p, i}=0.160-0.074 \frac{\sigma_{i}}{\sigma_{j}+\sigma_{k}}+0.028\left(\frac{\sigma_{i}}{\sigma_{j}+\sigma_{k}}\right)^{2},
$$

where $\mu_{c p, i}$ is the creep Poisson's ratio corresponding to the principal stress direction and $\sigma_{i}$ is the principal stress. For convenience in engineering practice, the effect of Poisson's ratio caused by creep is established based on a linear elastic formula. The transformation matrix $[A]$, which considers the influence of the creep Poisson's ratio, can be expressed as follows:

$$
[A]=\left[\begin{array}{cccccc}
1 & -\mu_{c p, 2} & -\mu_{c p, 3} & 0 & 0 & 0 \\
-\mu_{c p, 1} & 1 & -\mu_{c p, 3} & 0 & 0 & 0 \\
-\mu_{c p, 1} & -\mu_{c p, 2} & 1 & 0 & 0 & 0 \\
0 & 0 & 0 & 2+\mu_{c p, 2}+\mu_{c p, 3} & 0 & 0 \\
0 & 0 & 0 & 0 & 2+\mu_{c p, 1}+\mu_{c p, 3} & 0 \\
0 & 0 & 0 & 0 & 0 & 2+\mu_{c p, 1}+\mu_{c p, 2}
\end{array}\right] .
$$

For axially compressed CFST columns, owing to $0>\sigma 1=\sigma 2>\sigma 3$, equation (34) can be expressed as follows:

$$
\begin{aligned}
& \mu_{c p, 1}=\mu_{c p, 2}=0.160-\frac{0.074 q^{\prime}}{1+q^{\prime}}+\left(\frac{0.028 q^{\prime}}{1+q^{\prime}}\right)^{2}, \\
& \mu_{c p, 3}=0.160-\frac{0.037}{q^{\prime}}+\frac{0.007}{q^{\prime 2}},
\end{aligned}
$$

where $q^{\prime}$ is the hoop stress coefficient.

3.2. 3D Nonlinear Creep Constitutive Model. The total strain at time $t$ should include three parts: the first part is the elastic strain at loading age $\tau$ and the corresponding creep strain; the second part is the elastic strain and the corresponding creep strain caused by a stress increment in the $(t-\tau)$ period; the third part is the shrinkage strain $\left(\varepsilon^{S}\right)$ and the temperature strain $\left(\varepsilon^{T}\right)$. Therefore, the total strain can be expressed as follows [24]:

$$
\begin{aligned}
\{\varepsilon(t)\}= & {[A]\{\sigma(\tau)\} J(t, \tau, \sigma)+\int_{\tau}^{t} J(t, \tau, \sigma)[A]\left\{\frac{\mathrm{d} \sigma(\tau)}{\mathrm{d} \tau}\right\} \mathrm{d} \tau } \\
& +\left\{\varepsilon^{S}(t)+\varepsilon^{T}(t)\right\},
\end{aligned}
$$

where $J(t, \tau, \sigma)$ is the creep compliance function and is expressed as follows:

$$
J(t, \tau, \sigma)=C(t, \tau, \sigma)+\frac{1}{E(\tau)(1-d(\tau))},
$$

where $E(\tau)$ is the elastic modulus of concrete at loading time $\tau$ and $C(t, \tau, \sigma)$ is the creep function obtained as follows:

$$
\begin{aligned}
C(t, \tau, \sigma) & =\frac{1}{(1-d(\tau))} C(t, \tau) \\
& =\frac{1}{(1-d(\tau))} \sum_{i=1}^{m} a_{i}(\tau)\left[1-e^{-\lambda_{i}(t-\tau)}\right],
\end{aligned}
$$

$$
C(t, \tau)=\sum_{i=1}^{m} a_{i}(\tau)\left[1-e^{-\lambda_{i}(t-\tau)}\right]
$$

where $\mathrm{d}(\tau)$ is the damage factor related to the concrete stress states, whose value is in the range $[0,1], C(t, \tau)$ must be expressed in the form of a Dirichlet series to avoid integrating the stress histories of the entire time, and $a_{i}(\tau)$ and $\lambda_{i}$ can be determined as follows:

(1) High precision is generally already achieved when $m$ is equal to 4 and $\lambda_{1}=1, \lambda_{2}=0.1, \lambda_{3}=0.01$, and $\lambda_{4}=0.001$ [22].

(2) If the creep effect of time $t$ is calculated, then $(t-\tau)$ must be divided into $n$ segments $\left(t_{1}, t_{2}, \ldots, t_{i}, \ldots, t_{n}\right.$ $\left.t_{i}>t_{0}, t_{n}=t\right)$, where $\tau_{0}$ is the curing time and $C\left(t_{i}, \tau\right)$ is calculated according to the equations given by the corresponding prediction models.

(3) By substituting $C\left(t_{i}, \tau\right)$ and $\lambda_{i}$ into equation (41), the relationship between $a_{i}(\tau)$ and $C\left(t_{i}, \tau\right)$ can be expressed as follows: 


$$
\begin{aligned}
& {\left[\begin{array}{cccc}
1-e^{-\lambda_{1}\left(t_{1}-\tau\right)} & 1-e^{-\lambda_{2}\left(t_{1}-\tau\right)} & \ldots & 1-e^{-\lambda_{m}\left(t_{1}-\tau\right)} \\
1-e^{-\lambda_{1}\left(t_{2}-\tau\right)} & 1-e^{-\lambda_{2}\left(t_{2}-\tau\right)} & \ldots & 1-e^{-\lambda_{m}\left(t_{2}-\tau\right)} \\
\vdots & \vdots & \vdots & \vdots \\
1-e^{-\lambda_{1}\left(t_{n}-\tau\right)} & 1-e^{-\lambda_{2}\left(t_{n}-\tau\right)} & 1-e^{-\lambda_{3}\left(t_{n}-\tau\right)} & 1-e^{-\lambda_{m}\left(t_{n}-\tau\right)}
\end{array}\right]\left\{\begin{array}{c}
a_{1}(\tau) \\
a_{2}(\tau) \\
\vdots \\
a_{m}(\tau)
\end{array}\right\}=\left\{\begin{array}{c}
C\left(t_{1}, \tau\right) \\
C\left(t_{2}, \tau\right) \\
\vdots \\
C\left(t_{n}, \tau\right)
\end{array}\right\},} \\
& {[N]_{n \times m}=\left[\begin{array}{cccc}
1-e^{-\lambda_{1}\left(t_{1}-\tau\right)} & 1-e^{-\lambda_{2}\left(t_{1}-\tau\right)} & \ldots & 1-e^{-\lambda_{m}\left(t_{1}-\tau\right)} \\
1-e^{-\lambda_{1}\left(t_{2}-\tau\right)} & 1-e^{-\lambda_{2}\left(t_{2}-\tau\right)} & \ldots & 1-e^{-\lambda_{m}\left(t_{2}-\tau\right)} \\
\vdots & \vdots & \vdots & \vdots \\
1-e^{-\lambda_{1}\left(t_{n}-\tau\right)} & 1-e^{-\lambda_{2}\left(t_{n}-\tau\right)} & 1-e^{-\lambda_{3}\left(t_{n}-\tau\right)} & 1-e^{-\lambda_{m}\left(t_{n}-\tau\right)}
\end{array}\right]} \\
& \{a\}_{m \times 1}=\left\{\begin{array}{c}
a_{1}(\tau) \\
a_{2}(\tau) \\
\vdots \\
a_{m}(\tau)
\end{array}\right\} \\
& \{b\}_{n \times 1}=\left\{\begin{array}{c}
C\left(t_{1}, \tau\right) \\
C\left(t_{2}, \tau\right) \\
\vdots \\
C\left(t_{n}, \tau\right)
\end{array}\right\} \text {. }
\end{aligned}
$$

(4) Finally, $\{a\} m \times 1$ is determined using the leastsquares method, which is expressed as follows:

$$
\{a\}_{m \times 1}=\left[N^{T} N\right]_{m \times m}^{-1}\left[N^{T} b\right]_{m \times 1} .
$$

3.3. Numerical Analysis Method. Regarding the creep and shrinkage of the CFST columns, the shrinkage of concrete is restrained by the steel tube, and the concrete core that contacts the steel tube is pulled. This results in tensile strain and a corresponding creep strain. Moreover, the creep deformation of the concrete core caused by the load is partially responsible for the load transfer to the steel tube. Out of the many analysis methods, the method of step-by-step recurrence can handle this complex process easily and can also be combined with FE software. Thus, this method has been widely used in practical engineering projects [12]. Equation (38) indicates that the creep strain at $t_{n}$ and $t_{n+1}$ can be expressed as follows:

$$
\begin{aligned}
&\left\{\begin{array}{l}
\left\{\mathcal{E}^{c}\left(t_{n}\right)\right\}=[A]\left[\left\{\Delta \sigma_{0}\right\} C\left(t_{n}, t_{0}, \sigma_{t_{0}}\right)+\cdots+\left\{\Delta \sigma_{n-1}\right\} C\left(t_{n}, t_{n-1}, \sigma_{t_{n-1}}\right)\right] \\
\left\{\mathcal{E}^{c}\left(t_{n+1}\right)\right\}=[A]\left[\left\{\Delta \sigma_{0}\right\} C\left(t_{n+1}, t_{0}, \sigma_{t_{0}}\right)+\cdots+\left\{\Delta \sigma_{n}\right\} C\left(t_{n+1}, t_{n}, \sigma_{t_{n}}\right)\right]
\end{array}\right. \\
&\left\{\Delta \varepsilon^{c}\left(t_{n+1}\right)\right\}=[A]\left\{\Delta \sigma_{0}\right\}\left[C\left(t_{n+1}, t_{0}, \sigma_{t_{0}}\right)-C\left(t_{n}, t_{0}, \sigma_{t_{0}}\right)\right]+\cdots+\left\{\Delta \sigma_{n-1}\right\}\left[C\left(t_{n+1}, t_{n-1}, \sigma_{t_{n-1}}\right)-C\left(t_{n}, t_{n-1}, \sigma_{t_{n-1}}\right)\right] \\
& \quad+[A]\left\{\Delta \sigma_{n}\right\}\left[C\left(t_{n+1}, t_{n}, \sigma_{t_{n}}\right)\right] \\
& C\left(t_{n+1}, t_{j}, \sigma_{t_{j}}\right)-C\left(t_{n}, t_{j}, \sigma_{t_{j}}\right)=\frac{1}{\left(1-d\left(t_{j}\right)\right)} \sum_{i=1}^{m} a_{i}\left(t_{j}\right) e^{-\lambda_{i}\left(t_{n}-t_{j}\right)}\left[1-e^{-\lambda_{i} \Delta t_{n+1}}\right] .
\end{aligned}
$$

By substituting equation (48) into equation (47), it can be seen that the creep strain increment between the adjacent time increment steps has a recurrence relationship, which can be expressed as follows: 


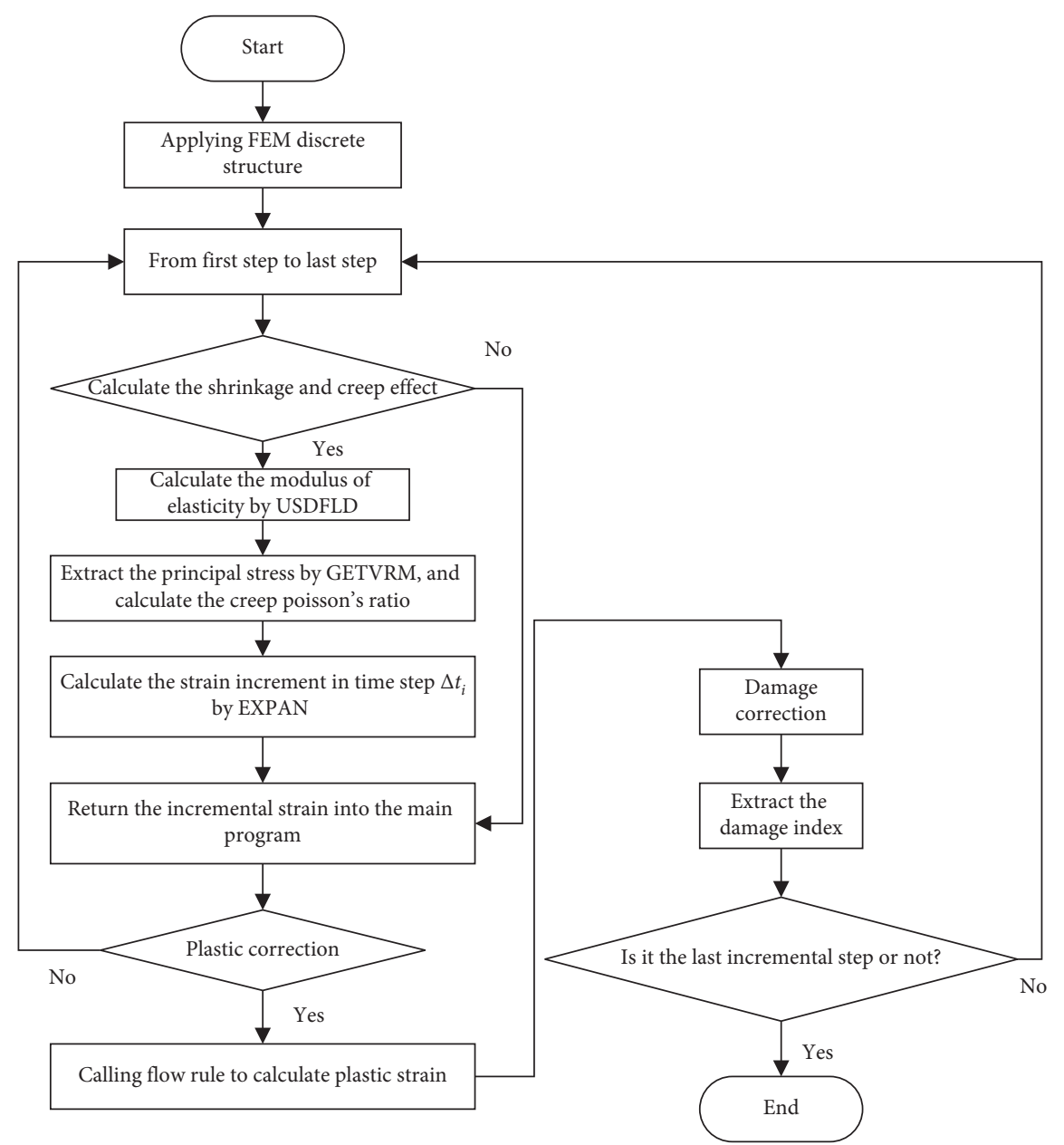

FIgURE 4: Computation program flowchart of the creep and shrinkage effects.

$$
\begin{gathered}
\left\{\Delta \varepsilon\left(t_{n}\right)^{c}\right\}=\sum_{i=1}^{m}\{\omega(i, n-1)\}\left(1-e^{-\lambda_{i} \Delta t_{n}}\right), \\
\left\{\begin{array}{l}
\{\omega(i, n)\}=\frac{1}{\left(1-d\left(t_{n-1}\right)\right)}\{\omega(i, n-1)\} e^{-\lambda_{i} \Delta t_{n-1}} \\
+\frac{1}{\left(1-d\left(t_{n}\right)\right)}[A]\left\{\Delta \sigma_{n}\right\} a_{i}\left(t_{n}\right), \\
\{\omega(i, 1)\}=\frac{1}{\left(1-d\left(t_{0}\right)\right)}[A]\left\{\Delta \sigma_{0}\right\} a_{i}\left(t_{0}\right) .
\end{array}\right.
\end{gathered}
$$

\section{Realization and Verification of Numerical Calculation Program}

4.1. Program of Numerical Calculation. A corresponding numerical calculation program was developed using the FORTRAN programming language, according to the analysis model of the 3D nonlinear creep and shrinkage effects, and the powerful secondary development function of ABAQUS.
Two user subroutines (USDFLD and UEXPAN) and one utility routine (GETVARM) are required to implement creep analysis through the ABAQUS secondary platform.

The purpose of USDFLD is to determine the evolution of the concrete elastic modulus with age. First, the elastic modulus is defined as a function of field variables in the main program. Next, the field variables are specified in USDFLD at each time increment step.

The function of UEXPAN is to calculate the strain increment caused by the creep and shrinkage at each time increment step. Because shrinkage is independent of stress, the shrinkage strain increment can be calculated according to the formulas provided by different models. Remarkably, when calculating the current creep strain for the creep strain increment using equation (49), it is necessary to call $\omega(i$, $n-1)$, which is stored during a previous step, owing to the recurrence relation between the adjacent time increment steps. In this case, the solution-dependent state variables (SDVs) are required to store $\omega(i, n)$.

The utility routine GETVRM is used to extract the variable value of the material points at each moment, including the stress and strain values and the SDVs. Subsequently, they transfer them to the UEXPAN subroutine. The 
TABLe 1: Parameters of the CFST specimens.

\begin{tabular}{|c|c|c|c|c|}
\hline & Specimen number & Specimen details $(\mathrm{mm})$ & $N_{\mathrm{L}}(\mathrm{kN})$ & $n_{\mathrm{c}}$ \\
\hline $\mathrm{Fu}[6]$ & $0.46-\mathrm{I}$ & $138 \times 2.57 \times 380$ & 420 & 0.46 \\
\hline $\mathrm{Fu}[6]$ & $0.46-\mathrm{II}$ & $138 \times 2.49 \times 380$ & 420 & 0.46 \\
\hline $\mathrm{Fu}[6]$ & $0.72-\mathrm{I}$ & $138 \times 2.57 \times 380$ & 679 & 0.72 \\
\hline $\mathrm{Fu}[6]$ & $0.72-\mathrm{II}$ & $138 \times 2.53 \times 380$ & 679 & 0.72 \\
\hline $\operatorname{Lin}[24]$ & $0.38-\mathrm{I}$ & $108 \times 4 \times 330$ & 377 & 0.38 \\
\hline $\operatorname{Lin}[24]$ & $0.8-\mathrm{I}$ & $108 \times 4 \times 330$ & 793 & 0.8 \\
\hline
\end{tabular}

Note. $N_{\mathrm{L}}$ is the long-term loading load and $n_{\mathrm{c}}$ is the load ratio, which is the ratio of the initial stress of concrete core $\left(\sigma_{0}\right)$ to the average cylinder compressive strength $\left(f_{\mathrm{c}}\left(t_{0}\right)\right), \sigma_{0}=\left(E_{c}\left(t_{0}\right) / E_{s} A_{s}+E_{c}\left(t_{0}\right) A_{c}\right) N_{L}$.

TABLE 2: Mix proportion of the concrete $\left(\mathrm{kg} \cdot \mathrm{m}^{-3}\right)$.

\begin{tabular}{llllll}
\hline & Cement & Water & Fine aggregate & Coarse aggregate & Superplasticizer \\
\hline Fu [6] & 412 & 192 & 648 & 1106 & 2.88 \\
Lin [24] & 437 & 140 & 560 & 1200 & 22.3 \\
\hline
\end{tabular}

TABle 3: Material parameters of concrete.

\begin{tabular}{lccr}
\hline & Age (day) & $f_{\mathrm{c}}\left(t_{0}\right)(\mathrm{MPa})$ & $E_{\mathrm{c}}\left(t_{0}\right)(\mathrm{GPa})$ \\
\hline Fu [6] & 28 & 44.2 & 31.4 \\
Lin [24] & 28 & 64.9 & 36.7 \\
\hline
\end{tabular}

Note. $f_{\mathrm{c}}\left(t_{0}\right)$ is the average compressive strength of $\Phi 150 \times 300 \mathrm{~mm}$ specimen and $E_{\mathrm{c}}\left(t_{0}\right)$ is the elastic modulus of the specimen.

TABLE 4: Material parameters of steel tubes.

\begin{tabular}{lccc}
\hline & Yield strength $(\mathrm{MPa})$ & $E_{\mathrm{s}}(\mathrm{GPa})$ & 199 \\
\hline Fu [6] & 299.3 & 199 & Poisson's ratio \\
Lin [24] & 345 & 206 & 0.28 \\
\hline
\end{tabular}

subroutine function and mutual call processes are shown in Figure 4.

4.2. Program Validation. Creep tests on short CFST columns under different stress levels have been conducted by Fu [6] and Lin [25], respectively.

The specimen details, loadings, and stress levels are listed in Table 1. The mix proportion of the concrete is presented in Table 2, and the material parameters of the concrete core and steel tubes are presented in Tables 3 and 4 . These tests were carried out in laboratories, where the temperature was relatively constant. The strain gauges were located in the middle of the specimens. The equipment used to perform the creep test in these experiments is shown in Figure 5. Loading was achieved through hydraulic jacks in conjunction with the force sensors.

In this analysis, the prediction model B4 was chosen because this model classified creep either as drying creep or as basic creep. For the simulation conducted in this experiment, it was considered that the concrete core did not exchange humidity with the external environment by excluding the drying creep. Moreover, the moisture content decreased via cement hydration. The relative humidity of the concrete core was taken as $85 \%$, according to the actual measurement results reported by Zhang et al. [26]. The relevant parameters of the $\mathrm{B} 4$ model are listed in Table 5.
The analysis was implemented using the FE package ABAQUS 6.14. The steel tubes were modeled by C3D8I, which can improve the convergence of nonlinear analysis. The concrete core and the steel-concrete interface were modeled by C3D8 and hard contact, respectively, as shown in Figure 6. In the absence of load-displacement data for the specimen, the dilation angle was calculated according to equation (29). The parameters of UCCDP are listed in Table 6, and the FE models are presented in Figure 6. The comparison between the measured data and the analysis results is presented in Figures 7-8.

The results revealed that the linear creep theory (L) and nonlinear creep theory (NL) have little difference when the stress level of the concrete core is lower (less than 0.6), and both theories could approximate the experimental results. However, for the specimens with a higher stress level (greater than 0.6), the results of the linear and nonlinear creep theory were obviously different. For the experiment conducted by $\mathrm{Fu}$ [6], after 110 days of loading, the result obtained using nonlinear creep theory was approximately $84 \%$ more than that obtained using linear creep theory. Moreover, the difference in relation to the experiment conducted by Lin [25] was $72 \%$. It was observed that the calculated results of nonlinear creep theory are in agreement with the measured results. Thus, the reliability of the proposed model was confirmed. 


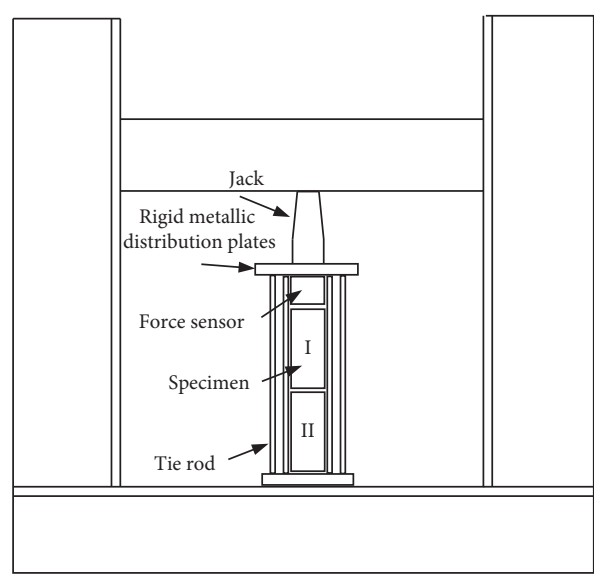

(a)

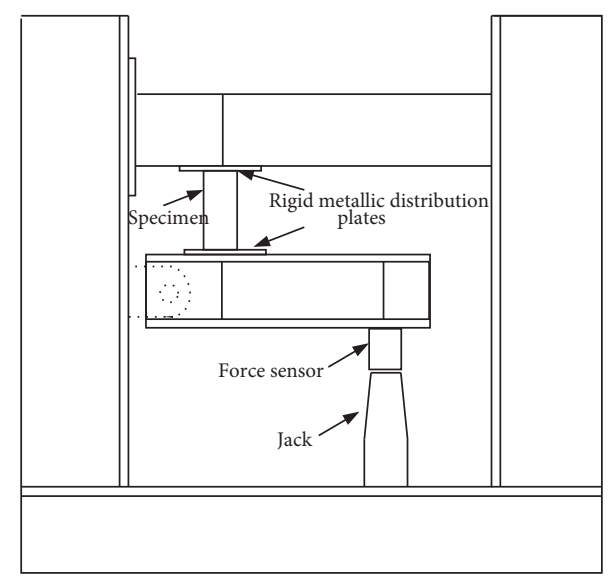

(b)

Figure 5: Creep test apparatus: (a) conducted by Fu [6] and (b) Lin [25].

TABle 5: Material constants for the B4 creep model $\left(10^{-6} / \mathrm{MPa}\right)$.

\begin{tabular}{lcccc}
\hline & $q_{2}$ & $q_{3}$ & $q_{4}$ & \\
\hline Fu [6] & 110.88 & 6.91 & 2.47 & \\
Lin [24] & 35.11 & 2.00 & 0.84 & 0 \\
\hline
\end{tabular}

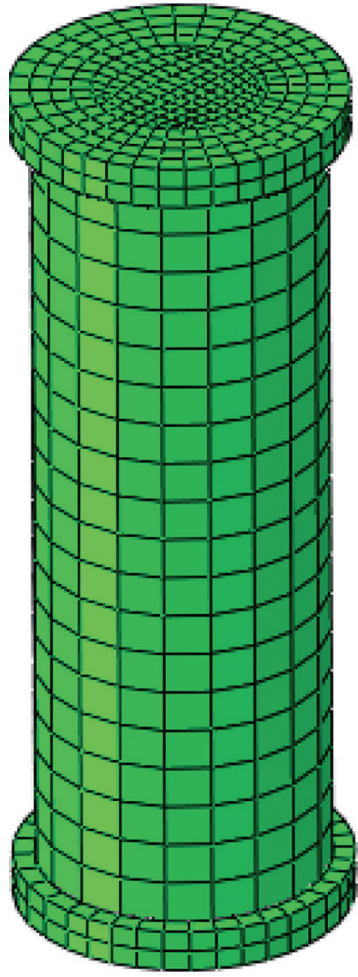

(a)

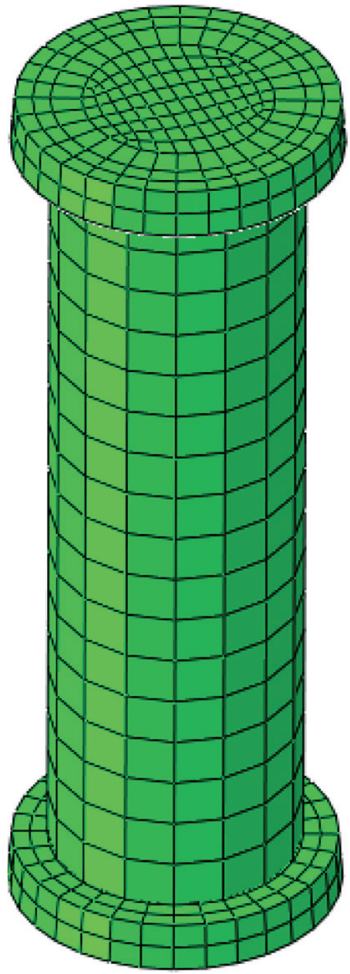

(b)

Figure 6: The FE models: (a) Fu [6] and (b) Lin [24].

TABle 6: Parameter setting of UCCDP.

\begin{tabular}{lccccr}
\hline & Dilation $\left(^{\circ}\right)$ & Eccentricity ratio & $f_{b 0} / f_{c 0}$ & $K_{c}$ & Viscosity coefficient \\
\hline Fu [6] & 27.5 & 0.1 & 1.16 & 0.759 & 0.0001 \\
Lin [24] & 34.1 & 0.1 & 1.16 & 0.759 & 0.0001 \\
\hline
\end{tabular}




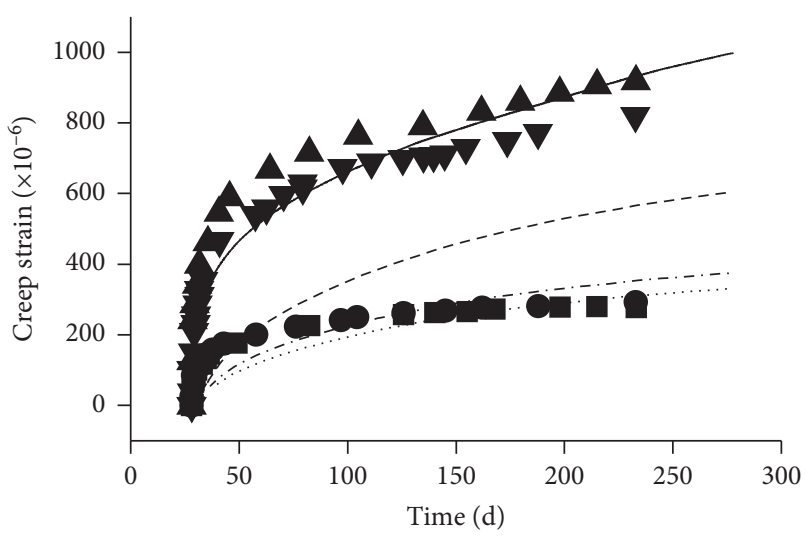

$$
\begin{aligned}
& \Delta \quad \text { 0.72-I measured } \quad \nabla \quad 0.72 \text {-II measured } \\
& \text { - - } 0.72-\mathrm{L} \quad 0.72-\mathrm{N} \\
& \text { - } 0.46-\mathrm{I} \quad \mathbf{0} 0.46-\mathrm{II} \\
& 0.46-\mathrm{L} \quad-\cdot \cdot 0.46-\mathrm{NL}
\end{aligned}
$$

FIgURE 7: Calculated concrete creep strain curve (Fu [6]).

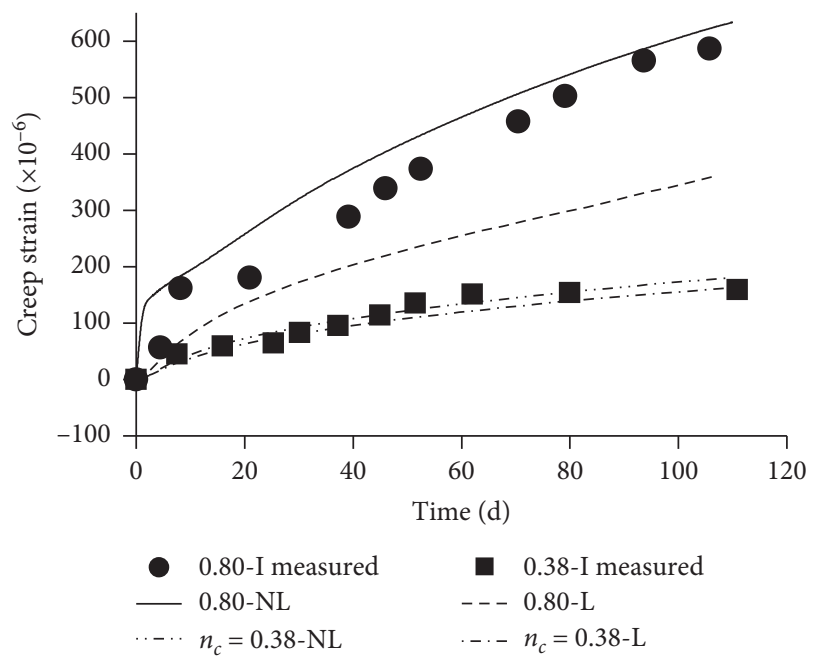

Figure 8: Calculated concrete creep strain curve (Lin [24]).

\section{Conclusions}

This study can be summarized as follows:

(1) A new theoretical framework for 3D nonlinear creep effect analysis was proposed to accurately analyze the nonlinear creep effect of short CFST columns with an axial load, and the corresponding numerical analysis method was established.

(2) A new damaged plasticity model for uniform confined concrete (UCCDP) was proposed, and the calibration methods of the key parameters were provided.

(3) An analysis program was developed using the FORTRAN programming language based on the ABAQUS secondary platform. The results revealed that this method can easily realize nonlinear creep effect analysis for short CFST columns under axial compression with a certain amount of accuracy.
Moreover, it should be noted that the method proposed in this study is mainly applicable to the analysis of the concrete core's nonlinear creep effect under a uniform constraint. For long CFST columns subjected to axial load, or short columns subjected to an eccentric load, the concrete core is no longer under a uniform constraint, and further investigation is required for a method of analyzing the nonlinear creep effect.

\section{Data Availability}

The data used to support the findings of this study are available from the corresponding author upon request.

\section{Conflicts of Interest}

The authors declare no conflicts of interest.

\section{Acknowledgments}

This work was supported by the Major Program of Technological Research and Development of China Railway Ministry "Experimental Study on the Influence of Creep and Shrinkage of Continuous Beam-Arch Bridge $(90+180+90 \mathrm{~m})$ in Beijing-Shanghai High-Speed Railway" (2008G031-K). The financial support is highly appreciated.

\section{References}

[1] W. O. Oyawa, K. Sugiura, and E. Watanabe, "Polymer concrete-filled steel tubes under axial compression," Construction and Building Materials, vol. 15, no. 4, pp. 187-197, 2001.

[2] F. Aslani, B. Uy, Z. Tao, and F. Mashiri, "Predicting the axial load capacity of high-strength concrete filled steel tubular columns," Steel and Composite Structures, vol. 19, no. 4, pp. 967-993, 2015.

[3] Y. S. Ma and Y. F. Wang, "Creep of high strength concrete filled steel tube columns," Thin-Walled Structures, vol. 53, pp. 91-98, 2012.

[4] Y. Wang, Y. Geng, G. Ranzi, and S. Zhang, "Time-dependent behaviour of expansive concrete-filled steel tubular columns," Journal of Constructional Steel Research, vol. 67, no. 3, pp. 471-483, 2011.

[5] E. Hamed, "Nonlinear creep response of reinforced concrete beams," Journal of Mechanics of Materials and Structures, vol. 7, no. 5, pp. 435-460, 2012.

[6] X. B. Fu, Long-Term Behaviour of Axially Loaded Concrete Filled Steel Tubular Stub Columns under High Stress, Harbin Institute of Technology, Harbin, China, 2013.

[7] Y. S. Ma, Y. F. Wang, and Z. K. Mao, "Creep effects on dynamic behavior of concrete filled steel tube arch bridge," Structural Engineering and Mechanics, vol. 37, no. 3, pp. 321-330, 2011.

[8] B. Han, H. B. Xie, L. Zhu, and P. Jiang, "Nonlinear model for early age creep of concrete under compression strains," Construction and Building Materials, vol. 147, pp. 203-211, 2017.

[9] Z. X. Li and J. C. Qian, "Creep damage analysis and its application to nonlinear creep of reinforced concrete beam," Engineering Fracture Mechanics, vol. 34, no. 4, pp. 851-860, 1989. 
[10] C. Mazzotti and M. Savoia, "Nonlinear creep damage model for concrete under uniaxial compression," Journal of Engineering Mechanics, vol. 129, no. 9, pp. 1065-1075, 2003.

[11] E. Hamed, "Modelling of creep in continuous RC beams under high levels of sustained loading," Mechanics of Timedependent Materials, vol. 18, no. 3, pp. 589-609, 2014.

[12] H. D. Huang and Z. F. Xiang, "Nonlinear creep analysis method for concrete structures," Engineering Mechanics, vol. 31, pp. 96-102, 2014.

[13] D. J. Zhang, Y. F. Wang, and Y. Lei, "A new creep model for concrete filled steel tube columns under axial compression," China Civil Engineering Journal, vol. S2, 2010.

[14] F. X. Li, "Spatial structural behaviour and time-dependent analysis of composite cable stayed bridge," Doctoral thesis, Tsinghua University, Beijing, China, 2011.

[15] Z. P. Bazant, M. Jirásek, M. Hubler, and I. Carol, "RILEM draft recommendation: TC-242-MDC multi-decade creep and shrinkage of concrete: material model and structural analysis. model B4 for creep, drying shrinkage and autogenous shrinkage of normal and high-strength concretes with multi-decade applicability," Materials and Structures, vol. 48, pp. 753-770, 2015.

[16] J. Lubliner, J. Oliver, S. Oller, and E. Oñate, "A plastic-damage model for concrete," International Journal of Solids and Structures, vol. 25, no. 3, pp. 299-326, 1989.

[17] J. Lee and G. L. Fenves, "Plastic-damage model for cyclic loading of concrete structures," Journal of Engineering Mechanics, vol. 124, no. 8, pp. 892-900, 1998.

[18] J. Zhang and J. Li, "Investigation into Lubliner yield criterion of concrete for 3D simulation," Engineering Structures, vol. 44, pp. 122-127, 2012.

[19] J. F. Jiang and Y. F. Wu, "Identification of material parameters for Drucker-Prager plasticity model for FRP confined circular concrete columns," International Journal of Solids and Structures, vol. 49, no. 3-4, pp. 445-456, 2012.

[20] Z. Tao, Z. B. Wang, and Q. Yu, "Finite element modelling of concrete-filled steel stub columns under axial compression," Journal of Constructional Steel Research, vol. 89, pp. 121-131, 2013.

[21] Y. B. Wang and J. Y. R. Liew, "Constitutive model for confined ultra-high strength concrete in steel tube," Construction and Building Materials, vol. 126, pp. 812-822, 2016.

[22] L. Charpin, Y. L. Pape, É. Coustabeau et al., "A 12 year EDF study of concrete creep under uniaxial and biaxial loading," Cement \& Concrete Research, vol. 103, p. S0008884617305914, 2017.

[23] A. M. Neville, W. H. Dilger, and J. J. Brooks, Creep of Plain and Structural Concrete, Construction Press, New York, NY, USA, 1983.

[24] S. W. Li, Y. Q. Yang, Q. H. Pu, D. Yang, B. L. Sun, and X. B. Li, "Three-dimensional nonlinear creep and shrinkage effectsof a long-span prestressed concrete box girder bridge," Structural Concrete, vol. 20, no. 2, pp. 638-649, 2019.

[25] J. Lin, "The creep of core concrete and its influence on the mechanical performance of the axially compressed high strength concrete filled steel tubular member," Masters thesis, University of Shantou, Guangdong, China, 2002.

[26] J. Zhang, J. Wang, and Y. Gao, "Moisture movement in earlyage concrete under cement hydration and environmental drying," Magazine of Concrete Research, vol. 68, no. 8, pp. 391-408, 2016. 